Background and aims Children born before 32 weeks of gestational age (GA) have increased risk of neurological, sensory, cognitive and behavioural problems. The latter become evident at school age, but follow-up is rarely continued up to this time. We present preliminary results of ongoing follow-up at school age of the Italian ACTION area-based cohort.

Methods All infants born $<32$ weeks GA in 2003-2004 in three regions (Lazio, Tuscany and Friuli Venezia-Giulia) and survived to school-age were invited. The Kaufman Assessment Battery second edition (KABC-II) and selected items of NEPSY-II were used to assess cognitive and neuropsychological development. Only results for Lazio and Trieste area in FVG, where follow-up is already completed, are included (n 390, response rate 58\%).

Results Fifty-six percent of children (n 218) were males; 35\% (1379 were $\leq 28$ weeks GA. About $8 \%$ (n 30 ) had cerebral palsy; six children (1.5\%) were blind or almost blind, and $12(3.1 \%)$ required hearing aids. Twenty-two percent of children had KABC-II Mental Development Index (MPI) below average (29.9\% in children born $\leq 28$ weeks gestation, $\mathrm{p}=0.008)$. Lower MPI scores were associated with impaired neuropsychological abilities.

Conclusions While most children have cognitive level within normal range, lower KABC-II and NEPSY-II scores were found particularly in the more preterm group. Sensorimotor abilities were the most frequently compromised neuropsychological functions.

Acknowledgements The ACTION follow-up project was funded by the Italian Ministry of Health and by the Chiesi Farmaceutici S.p. A.

\section{PO-0390 EFFECT OF HYPOTHERMIA ON AMPLITUDE-INTEGRATED ELECTROENCEPHALOGRAM IN INFANTS WITH PERINATAL ASPHYXIA}

K Goeral, V Giordano, K Klebermass-Schrehof, M Weninger, A Berger, M Olischar. Department of Pediatrics and Adolescent Medicine - Division of Neonatology Intensive Care and Pediatric Neurology, Medical University of Vienna, Vienna, Austria

\subsection{6/archdischild-2014-307384.1036}

Background The amplitude-integrated electroencephalogram $(\mathrm{aEEG})$ is reliable for early prediction of outcome in asphyxiated neonates. Hypothermia influences the positive predictive value (PPV) of early aEEG delaying normalisation of background pattern.

Methods Forty-one neonates with hypoxic ischaemic encephalopathy (HIE) Sarnat stage II $(\mathrm{n}=24$ normothermia $(\mathrm{NT}), \mathrm{n}=$ 17 hypothermia (HT)) were included into analysis.

Firstly aEEGs of the first 3 days (d) of life were analysed for both groups (background pattern, sleep-wake cycling and seizure activity; descriptive analysis and calculation of a combined aEEG-score).

Secondly aEEG parameters were correlated with postnatal clinical parameters, severity of neuroimaging abnormalities and neurodevelopmental outcome.

Finally, the PV of aEEGs was compared between the groups. Results The rate of pathological aEEGs on d1 showed no significant difference between the groups (pathological aEEG: 64\% HT, 71\% for NT). On d3, the rate was significantly lower in the HT group than in the NT group $(18 \% \mathrm{HT}, 57 \%$ for NT, $\mathrm{p}=$ $0.045)$.

There was a significant difference in outcome: in the HT group $82 \%$ showed a normal outcome, compared to $43 \%$ in the NT group.
The PPV of a combinded aEEG-score was higher on $\mathrm{d} 1$ in the HT group than in the NT group and increased in both groups from d1-d3.

The lack of sleep-wake cycling in children treated with HT significantly correlated with severity of neuroimaging abnormalites $(p=0.05)$ and pathological outcome $(p=0.03)$. In contrast, there was no correlation between seizure activity and outcome.

Conclusion Our results reflect published data, underlining the importance of aEEG as early outcome predictor in neonatal HIE.

\section{PO-0391 LONGITUDINAL DEVELOPMENT OF LANGUAGE SKILLS IN PREMATURE INFANTS USING BAYLEY SCALES OF INFANT DEVELOPMENT-III. EFFECT OF PARENTAL EDUCATION}

${ }^{1} \mathrm{~V}$ Soubasi, ${ }^{2} \mathrm{~K}$ Velikos, ${ }^{2} \mathrm{M}$ Michalettou, ${ }^{2} \mathrm{~V}$ Papadopoulou, ${ }^{1} \mathrm{~K}$ Sarafidis, ${ }^{3} \mathrm{C}$ Nakas, ${ }^{1} \mathrm{~V}$ Drossou-Agakidou. ${ }^{1} 1 \mathrm{st}$ Department of Neonatology Aristotle University of Thessaloniki, Hippokration General Hospital, Thessaloniki, Greece; ${ }^{2}$ Department of Child Psychiatry, Hippokration General Hospital, Thessaloniki, Greece; ${ }^{3}$ Laboratory of Biometry, University of Thessaly, Volos, Greece

\subsection{6/archdischild-2014-307384.1037}

Background Preterm infants are at increased risk for language delay. Children in low socioeconomic status environments are exposed less often to experiences that promote language development. Parental education level has been associated with language scores.

Aim To assess the influence of sociodemographic variables on the longitudinal development of language skills in a cohort of premature infants.

Method Bayley-III scales were applied in 120 preterm infants ( $\leq$ 32 weeks) at a mean corrected age of 12 and 36 months. Preterm infants were divided in 2 groups according to their GA: A ( $\mathrm{n}=59,24-28 \mathrm{wks}), \mathrm{B}$ ( $\mathrm{n}=61,29-32 \mathrm{wks})$. All developmental assessments $(n=240)$ were performed by one researcher.

Results Mean (SD) Bayley-III Language scores [composite (CSs) and Subscale: Receptive (RS), Expressive (ES)] for the 2 groups are shown in the table. Group B showed a significant increase in CSs and subscale RS, ES scores overtime while Group A scores were stable for the CS and ES. There was a significant correlation between CSs, RS, ES language scores and parental education level only for the group B. No correlation was found with other demographics or complications of prematurity.

Conclusion Our findings argue that language development depends upon the grade of prematurity. ELBW infants show lower language performance not improving overtime as compared to VLBW. The more immature the less influence of parental education level. Very early language intervention with speech therapy may be especially important for the ELBW infants.

Abstract P0-0391 Table 1

\begin{tabular}{|c|c|c|c|c|}
\hline Language scale & $\begin{array}{c}\text { Group A } \\
\text { GA:26.4(1.1), BW:978(194) }\end{array}$ & & $\begin{array}{c}\text { Group B } \\
\text { GA:30.6(1.2)BW:1370(350) }\end{array}$ & \\
\hline CSs $12 \mathrm{mo}$ & $91,24 \pm 16.22$ & \multirow{2}{*}{$p=0.17$} & $90.61 \pm 17.29$ & \multirow{2}{*}{$p=0.0075$} \\
\hline CSs $36 \mathrm{mo}$ & $94,96 \pm 19.67$ & & $97.20 \pm 18.5$ & \\
\hline ES $12 \mathrm{mo}$ & $8.8 \pm 2.9$ & \multirow{2}{*}{$p=0.6$} & $8.08 \pm 3.2$ & \multirow{2}{*}{$p=0.04$} \\
\hline ES $36 \mathrm{mo}$ & $8.7 \pm 3.2$ & & $9.01 \pm 3.07$ & \\
\hline RS $12 \mathrm{mo}$ & $8.37 \pm 2.95$ & \multirow{2}{*}{$p=0,034$} & $8.65 \pm 3.2$ & \multirow{2}{*}{$P=0,008$} \\
\hline RS $36 \mathrm{mo}$ & $9.47 \pm 3.74$ & & $9.93 \pm 3.5$ & \\
\hline
\end{tabular}

